\title{
Awareness of Breast Cancer in Lower Socioeconomic Status Women Attending the Surgery Outpatient Department of a Tertiary Care Teaching Institution
}

\author{
S. Keerthana, Arcot Rekha \\ Saveetha Medical College and Hospital (SIMATS), Chennai, India \\ Email: keerthisankar98@gmail.com
}

How to cite this paper: Keerthana, S. and Rekha, A. (2019) Awareness of Breast Cancer in Lower Socioeconomic Status Women Attending the Surgery Outpatient Department of a Tertiary Care Teaching Institution. Case Reports in Clinical Medicine, 8, 205-215.

https://doi.org/10.4236/crcm.2019.88025

Received: June 29, 2019

Accepted: August 9, 2019

Published: August 12, 2019

Copyright $\odot 2019$ by author(s) and Scientific Research Publishing Inc. This work is licensed under the Creative Commons Attribution International License (CC BY 4.0).

http://creativecommons.org/licenses/by/4.0/

(c) (i) Open Access

\begin{abstract}
Background: Worldwide breast cancer represents nearly a quarter (25\%) of all cancers and is the most common female cancer. Objective: The present study was conducted to check the awareness of breast cancer warning signs \& symptoms, available investigations and treatment options among women of a suburban area in Chennai, Tamilnadu (India). Materials and Methods: A cross-sectional, prospective study was conducted amongst women attending the surgery outpatient department of a tertiary care teaching institution in Chennai, Tamilnadu (India), using a semi-structured questionnaire. The questionnaires were administered during one to one interview by trained research assistants. Results: The study population showed poor awareness of warning signs like changes in position of nipple, pulling in of nipple, nipple rash, changes in size of nipple, puckering/dimpling of breast skin colour changes in breast skin, lump under armpit, changes in size and shape of breast. Conclusion: The observations indicated that the level of awareness and knowledge about the presentation and management of breast cancer is suboptimal among women in Thandalam (suburban Chennai).
\end{abstract}

\section{Keywords}

Breast Cancer, Awareness, Questionnaire, Mammogram, Barriers, Screening, Chennai, Tamilnadu, India

\section{Introduction}

Worldwide Breast cancer represents nearly a quarter (25\%) of all cancers and is 
the most common female cancer. The number of cases is slightly higher in less developed regions than in more developed regions [1]. It is now the most common cancer in most cities in India and the second most common in rural area. Breast cancer accounts for $30.7 \%$ of all cancers in women in Chennai (National Cancer Registry Programme, based on Population Based Cancer Registry \& Hospital Based Cancer Registry).

Breast screening aims at detecting breast cancer at an early stage. Studies have shown that screening has significantly decreased the mortality from breast cancer. Numerous methods are available for early diagnosis of breast cancer including breast self examination (BSE), clinical based examination (CBE), examination by a physician or nurse, mammography, an X-ray of breast and magnetic resonance imaging (MRI) for high-risk women group.

The growing incidence of breast cancer worldwide stresses the greater need for a study of its rise and the need for awareness about it in developing nations. The people reach to the specialist doctor very late because of lack of awareness and low knowledge of breast cancer.

The aims of the present study that is conducted in a suburban area in Chennai are:

1) To check the awareness of the signs and symptoms of breast cancer;

2) To study the religious beliefs of the patients, if any;

3) To analyse the socioeconomic status of the study population;

4) To study the barriers to screening;

5) To analyse if they were aware of the various treatment modalities for breast cancer.

\section{Materials and Methods}

\subsection{Study Design}

It is a cross-sectional, prospective study conducted amongst women attending surgery outpatient department of Saveetha Medical College Hospital in Thandalam (a suburban area in Chennai) using a semi-structured questionnaire. The questionnaires were administered during one to one interview by trained research assistants. A Convenient sampling methodology was adopted for the study.

\subsection{Questionnaire Design}

A semi-structured questionnaire in English was developed after an extensive review of the literature and was validated by two experts. It included questions pertaining to breast cancer signs and symptoms, barriers to screening or treatment and available treatment modalities.

\subsection{Data Collection}

The study was conducted over 3 months. A total of 210 female subjects belonging to the reproductive age group (15 - 49 years) were included in the study who were outpatients in the department of surgery between January 10, 2019 and 
March 31, 2019. The trained research assistants described the purpose and process of the interview to the subjects and emphasised the confidentiality and anonymity of the responses. For the purpose of this study, informed consent was taken from all subjects.

\subsection{Data Management and Statistical Analysis}

The response to the questions was coded in "yes", "no" or "don't know" format. Age, religion, marital status and socioeconomic status were included as demographic factors. The modified Kuppuswamy socioeconomic scale (2018) was used for assessing the socioeconomic status of the patient, which uses parameters like education and occupation of the head of family along with the per-capita income of the family. The collected data were analysed using Microsoft excel.

The institutional review board of Saveetha Medical College and Hospital (SIMATS) has given approval for the project.

\section{Results}

\section{Characteristics of subjects}

Data were collected from 210 participants. The age of our subjects ranged from 18 - 76 years, of whom $83.3 \%$ were married and $16.7 \%$ were unmarried. $87.1 \%$ of our subjects were Hindus, followed by $7.1 \%$ of Muslims and 5.8\% Christians (Figure 1). As per census 2011, Hindus are a majority in Tamilnadu state constituting $85.58 \%$ of Tamilnadu population, followed by $6.12 \%$ of Christians and $5.86 \%$ of Muslims. The socioeconomic status of all the participants was calculated as per the modified Kuppuswamyscale (2018) and it showed that $54.3 \%$ belonged to the lower (V) class, $37.1 \%$ belonged to the upper lower (IV) class and the remaining to lower middle (III) class (Figure 2). Only 39\% of our subjects knew someone who had breast cancer among their friends and family.

The entire details of questions about knowledge of warning signs and symptoms of breast cancer are outlined in Table 1.

A lot of women were unaware that nipple changes are a feature of breast cancer. $54.8 \%$ of subjects believed that pain is a sign of breast cancer, given that carcinoma breast often presents as a painless lump (Figure 3). Only 59.5\% of participants were aware that bleeding from the nipple was a sign and only $45.2 \%$ were aware that pulling in of nipple was a sign of breast cancer (Figure 4), while about $82 \%$ were unaware that a nipple rash was a sign and $73 \%$ were unaware that a change in size of nipple was a sign of breast cancer. $74.8 \%$ of our subjects were aware that a lump in the breast is an ominous sign of breast cancer, while $64.8 \%$ of our subjects were unaware of breast skin colour change as a sign and $64.3 \%$ of our subjects were unaware that puckering/dimpling of breast skin as a sign of breast cancer. $1.9 \%$ of our subjects believed that nipple rash was not a sign of breast cancer and $5 \%$ of our subjects believed that breast skin colour change and change in size of nipple were not signs of breast cancer. Similarly, 


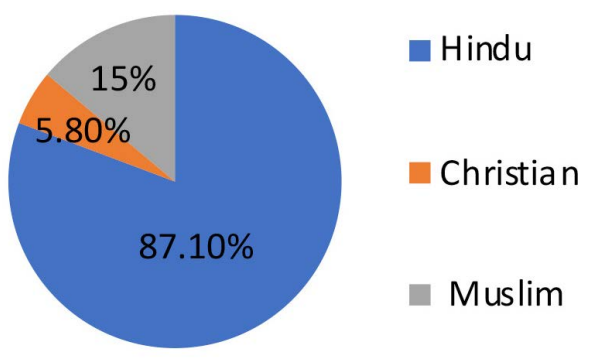

Figure 1. Religion distribution of participants.

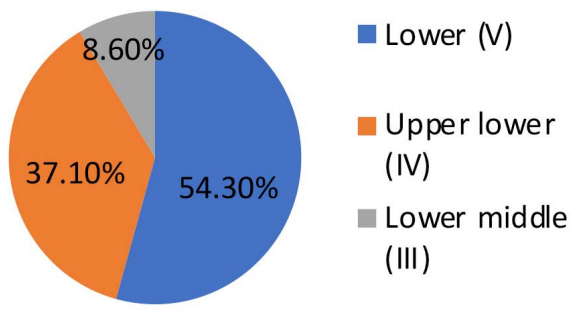

Figure 2. Socioeconomic status of participants.

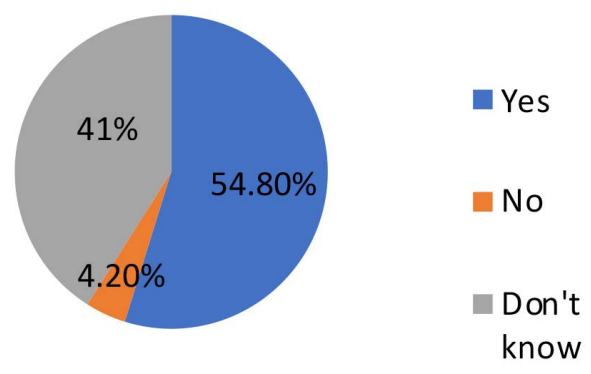

Figure 3. Pain in breast as a sign.

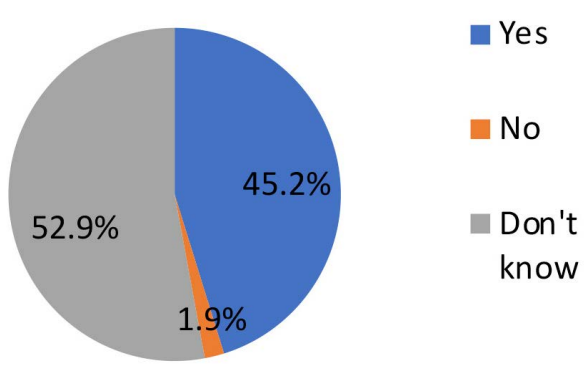

Figure 4. Pulling in of nipple as a sign.

$3.3 \%$ of our subjects thought that change in shape of the breast was not a sign and $2.8 \%$ of our subjects thought that change in Size of the breast was not a sign of breast cancer.

When we analysed the barriers to screening and seeing medical care, we found that "embarrassment" was the most significant barrier, accounting for $35.2 \%$ (Figure 5). Also, 18.1\% of our subjects felt that visiting the doctor would be expensive and that they cannot afford it while $74.8 \%$ of our subjects believed otherwise (Figure 6). 
Table 1. Knowledge about warning signs and symptoms of breast cancer.

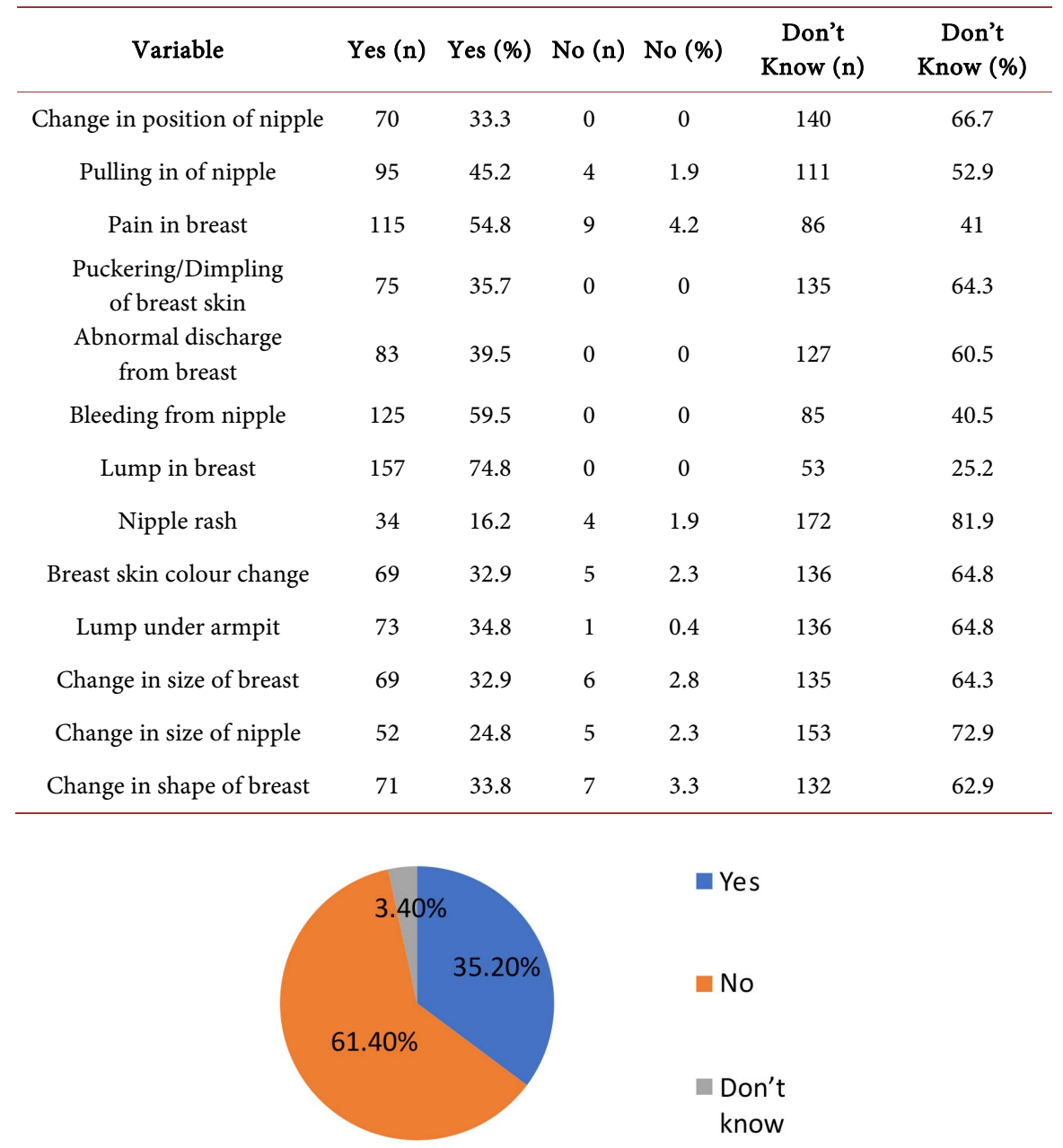

Figure 5. Embarrassment as a barrier.

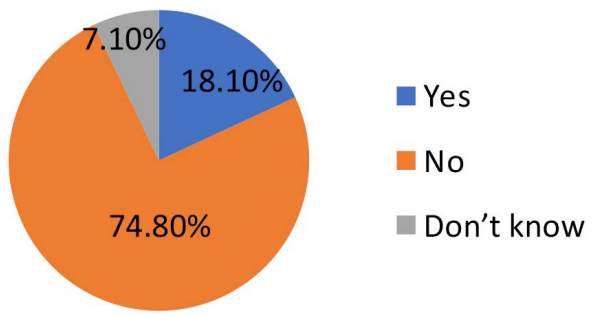

Figure 6. Financial constraints as a barrier.

The details of questions regarding various barriers are outlined in Table 2.

$56.2 \%$ of our subjects felt that clinical examination of the breasts is the best test for cancer breast, but only about $41.4 \%$ of our subjects were aware that mammogram is the best test. Knowledge about the various treatment options for breast cancer was found to be variable. 53.3\% of our subjects felt that treatment of cancer breast involved removal of the breast and 39\% of our subjects felt the treatment involved removal of the breast lump. The details of questions regarding available diagnostic and treatment modalities are outlined in Table 3. 
Table 2. Barriers to screening.

\begin{tabular}{|c|c|c|c|c|c|c|}
\hline Variable & Yes (n) & Yes $(\%)$ & No $(n)$ & No (\%) & $\begin{array}{c}\text { Don't } \\
\text { Know (n) }\end{array}$ & $\begin{array}{c}\text { Don't } \\
\text { Know (\%) }\end{array}$ \\
\hline Embarrassed to go and see the doctor & 74 & 35.2 & 129 & 61.4 & 7 & 3.4 \\
\hline Scared to go and see the doctor & 29 & 13.8 & 174 & 82.9 & 7 & 3.3 \\
\hline Worried about wasting the doctors time & 0 & 0 & 202 & 96.2 & 8 & 3.8 \\
\hline Find doctor difficult to talk to & 13 & 6 & 187 & 89 & 10 & 5 \\
\hline Difficult to make an appointment with the doctor & 0 & 0 & 197 & 93.8 & 13 & 6.2 \\
\hline Busy to make time to go to the doctor & 0 & 0 & 206 & 98.1 & 4 & 1.9 \\
\hline Seeing the doctor would be expensive/not enough money & 38 & 18.1 & 157 & 74.8 & 15 & 7.1 \\
\hline Difficult to arrange transport & 48 & 22.9 & 151 & 71.9 & 11 & 5.2 \\
\hline Worried about what the doctor might find & 15 & 7.2 & 191 & 90.9 & 4 & 1.9 \\
\hline Not feeling confident talking about symptoms & 6 & 3 & 193 & 91.9 & 11 & 5.1 \\
\hline Significant people in life would not approve & 6 & 2.9 & 187 & 89 & 17 & 8.1 \\
\hline Doctor would not understand the language & 11 & 5 & 195 & 92.9 & 4 & 2.1 \\
\hline Doctor would not understand the culture & 0 & 0 & 204 & 97.1 & 6 & 2.9 \\
\hline
\end{tabular}

Table 3. Awareness of diagnosis and treatment modalities.

\begin{tabular}{lcccccc}
\hline \multicolumn{1}{c}{ Variable } & Yes (n) & Yes (\%) & No (n) & No (\%) & Don't Know (n) & Don't know (\%) \\
\hline Best test for Ca. Breast is clinical examination & 118 & 56.2 & 3 & 1.4 & 89 & 42.4 \\
Best test for Ca. Breast is mammogram & 87 & 41.1 & 0 & 0 & 123 & 58.6 \\
Mammogram is a painful procedure & 21 & 10 & 8 & 3.8 & 181 & 86.2 \\
$\begin{array}{l}\text { Treatment for Ca. Breast is removal of the involved breast } \\
\text { Treatment for Ca. Breast is removal of the lump }\end{array}$ & 112 & 53.3 & 1 & 0.5 & 97 & 46.2 \\
$\begin{array}{l}\text { Treatment for Ca. Breast is removal of the breast and } \\
\text { radiotherapy }\end{array}$ & 71 & 33.8 & 1 & 0.5 & 138 & 60.5 \\
\hline
\end{tabular}

\section{Discussion}

This study was conducted to assess the awareness of breast cancer among women in a suburban area near Chennai.

When we studied the knowledge of our subjects about the warning signs and symptoms of breast cancer, we found that a lump in the breast is the most frequently identified sign by our subjects, followed by pain in the breast. These findings are quite consistent with the study done by Brijesh Sathian, et al. [2]. Majority of our subjects were also unaware of signs like lump under armpit, change in colour of breast skin.

When we analysed the various barriers to screening, the most frequently encountered barriers were embarrassment and unavailability of financial support which is supported by a study done by Kanaga, et al. 2011 [3]. Difficulty in Communication and Language was also reported as a barrier.

On studying the knowledge of our subjects about the screening methods and treatment options we found that more than $50 \%$ of our subjects felt that clinical 


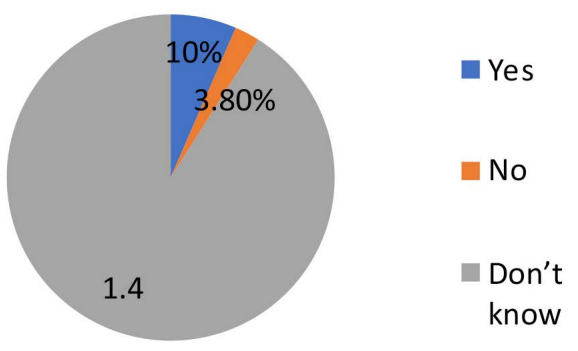

Figure 7. Mammogram is a painful procedure.

examination of the breasts is the best screening method and that the best treatment was removal of the involved breast. Also, $86.2 \%$ of our subjects thought that mammogram is a painful procedure (Figure 7).

Early breast cancer (EBC) constitutes only $30 \%$ of the breast cancer cases seen at different cancer centres in India whereas it constitutes $60-70 \%$ of cases in the developed world [4]. The incidence/mortality ratio of breast cancer in India is 0.48 [5]. A major factor for this high mortality is late diagnosis, as the majority of the patients present in advanced stages of the disease [6]. This is attributed to lack of awareness and also cultural taboos which make breast cancer a topic that is not freely discussed in India. The poor awareness about breast cancer is of concern and emphasises the need for increased awareness to be created amongst the population in general. Also, provision of subsidised mammograms to women at risk can be considered. Public health education programs can be initiated by the government and NGO's to generate awareness and also reduce fear, myths and misconceptions about breast cancer among the general population, with special focus on the rural and suburban areas. Breast cancer screening drives can be organised in PHCs in rural areas. Also, mobile breast cancer screening units can be made available for the benefit of women at risk who do not have access to other screening facilities.

\section{Conclusion}

In conclusion, we can infer from the present study that the women in Thandalam (suburban Chennai) show suboptimal awareness and knowledge of breast cancer warning signs, screening methods and treatment options. Immediate measures need to be implemented to build the capacity of women towards overcoming barriers and showing up for treatment.

\section{Limitations of This Study}

1) The sample size for a questionnaire-based study is small.

2) The women attending the surgical out-patient department of Saveetha Medical College and Hospital (SIMATS) may not be representative of the general population

\section{Conflicts of Interest}

The authors declare no conflicts of interest regarding the publication of this paper. 


\section{References}

[1] Malvia, S., Bagadi, S.A., Dubey, U.S. and Saxena, S. (2017) Epidemiology of Breast Cancer in Indian Women. Asia Pacific Journal of Oncology, 13, 289-295. https://doi.org/10.1111/ajco.12661

[2] Sathian, B., et al. (2014) Awareness of Breast Cancer Warning Signs and Screening Methods among Female Residents of Pokhara Valley, Nepal. Asian Pacific Journal of Cancer Prevention, 15, 4723-4726.

https://doi.org/10.7314/APJCP.2014.15.11.4723

[3] Kanaga, K.C., Nithiya, J. and Shatirah, M.F. (2011) Awareness of Breast Cancer and Screening Procedures among Malaysian Women. Asian Pacific Journal of Cancer Prevention, 12, 1965-1967.

[4] Nandakumar, A., et al. (1995) Survival in Breast Cancer: A Population-Based Study in Bangalore, India. International Journal of Cancer, 60, 593-596. https://doi.org/10.1002/ijc.2910600504

[5] Parkin, D.M., Pisani, P. and Ferlay, J. (2005) Global Cancer Statistics 2002. CA: $A$ Cancer Journal for Clinicians, 55, 74-108. https://doi.org/10.3322/canjclin.55.2.74

[6] Somdatta, P. and Baridalyne, N. (2008) Awareness of Breast Cancer in Women of an Urban Resettlement Colony. Indian Journal of Cancer, 45, 149-153. https://doi.org/10.4103/0019-509X.44662 


\section{Appendix: Questionnaire}

\section{Section A: Sociodemographic Profile}

Name:

Age:

Religion: Hindu/Christian/Muslim/Others

Marital status: Married/Unmarried

Education of patient: Illiterate/Primary school Certificate/Middle school Certificate/High school certificate/Intermediate or Diploma/ Graduate/Professional

Education of head of family: Illiterate/Primary school Certificate/Middle school Certificate/High school certificate/Intermediate or Diploma/Graduate/ Professional

Occupation of patient: Unemployed/Elementary occupation/Plant \& machine operators/Craft \& related trade workers/Skilled agricultural or fishery workers/Skilled workers or shop \& market sales workers/Clerks/ Technicians/ Professionals/Legislators or senior officials or Managers

Occupation of head of family: Unemployed/Elementary occupation/Plant \& machine operators/Craft \& related trade workers/Skilled agricultural or fishery workers/Skilled workers or shop \& market sales workers/Clerks/Technicians/ Professionals/Legislators or senior officials or Managers

Total monthly income of the family (Rs):

$<$ or $=6323 / 6327-18,949 / 18,953-31,589 / 31,591-47,262 / 47,266-63,178 / 63,182-$ $126,356 />126,360$

Socioeconomic status: Lower (V)/Upper lower (IV)/Lower middle (III)/Upper middle (II)/Upper (I)

Do you know anyone in your family/friends who has had breast cancer? Yes/No

\section{Section B: Knowledge of Breast Cancer Symptoms}

1) Do you think a change in the position of your nipple could be a sign of breast cancer?
a) Yes
b) No
c) Don't know

2) Do you think pulling in of your nipple could be a sign of breast cancer?
a) Yes
b) No
c) Don't know

3) Do you think pain in one of your breasts could be a sign of breast cancer?
a) Yes
b) $\mathrm{No}$
c) Don't know

4) Do you think puckering or dimpling of your breast skin could be a sign of breast cancer? 

a) Yes
b) No
c) Don't know

5) Do you think abnormal discharge from your breast could be a sign of breast cancer?
a) Yes
b) No
c) Don't know

6) Do you think bleeding from your nipple could be a sign of breast cancer?
a) Yes
b) No
c) Don't know

7) Do you think a lump in your breast could be a sign of breast cancer?
a) Yes
b) No
c) Don't know

8) Do you think a nipple rash could be a sign of breast cancer?
a) Yes
b) $\mathrm{No}$
c) Don't know

9) Do you think if your breasts change skin colour, this could be a sign of breast cancer?
a) Yes
b) No
c) Don't know

10) Do you think a lump under your armpit could be a sign of breast cancer?
a) Yes
b) No
c) Don't know

11) Do you think changes in the size of your breast could be signs of breast cancer?
a) Yes
b) No
c) Don't know

12) Do you think changes in the size of your nipple could be a sign of breast cancer?
a) Yes
b) No
c) Don't know

13) Do you think changes in the shape of your breast could be a sign of breast cancer?
a) Yes
b) No
c) Don't know

\section{Section C: Barriers to Screening}

1) Would you be too embarrassed to go and see the doctor?
a) Yes
b) No
c) Don't know

2) Would you be too scared to go and see the doctor?
a) Yes
b) No
c) Don't know

3) Would you be worried about wasting the doctor's time?
a) Yes
b) No
c) Don't know

4) Would you find your doctor difficult to talk to?
a) Yes
b) $\mathrm{No}$
c) Don't know

5) Would it be too difficult to make an appointment with the doctor?
a) Yes
b) No
c) Don't know 
6) Would you be too busy to make time to go to the doctor?
a) Yes
b) No
c) Don't know

7) Would seeing the doctor be too expensive and you don't have enough money?
a) Yes
b) No
c) Don't know

8) Would it be too difficult to arrange transport to the doctors clinic?
a) Yes
b) No
c) Don't know

9) Would worrying about what the doctor might find stop you from going to the doctor?
a) Yes
b) No
c) Don't know

10) Would not feeling confident talking about your symptoms with the doctor would keep you from seeing him/her?
a) Yes
b) No
c) Don't know

11) Would significant people in your life (e.g. husband/wife, sibling, relative or friend) not approve of you seeing a doctor or nurse?
a) Yes
b) No
c) Don't know

12) Would your doctor not understand your language?
a) Yes
b) $\mathrm{No}$
c) Don't know

13) Would your doctor not understand your culture?
a) Yes
b) $\mathrm{No}$
c) Don't know

\section{Section D: Investigations and Treatment Plan}

1) The best test for cancer breast is clinical examination.
a) Yes
b) No
c) Don't know

2) The best test for cancer breast is a mammogram.
a) Yes
b) No
c) Don't know

3) Mammogram is a painful procedure.
a) Yes
b) No
c) Don't know

4) Treatment for cancer breast is removal of the involved breast.
a) Yes
b) $\mathrm{No}$
c) Don't know

5) Treatment for cancer breast is removal of the lump.
a) Yes
b) No
c) Don't know

6) Treatment for cancer breast is removal of breast and radiotherapy.
a) Yes
b) No
c) Don't know 